\title{
Time-course analysis of the artemisinin biosynthesis, and expression of genes coding for artemisinin pathway enzymes, in response to exogenous salicylic and gibberellic acids
}

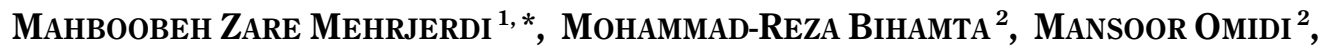 \\ MOHAMMAD-REZA NAGHAVI ${ }^{2}$, HASSAN SOLTANLOO ${ }^{3}$ \\ ${ }^{1}$ Department of Horticulture, College of Abouraihan, University of Tehran, Tehran, Iran \\ ${ }^{2}$ Department of Agronomy and Plant breeding, Agriculture College, University of Tehran, Karaj, Iran \\ ${ }^{3}$ Department of Genetic Engineering and Biotechnology, \\ Gorgan University of Agricultural Sciences and Natural Resources, Gorgan, Iran
}

\begin{abstract}
Artemisinin represents medicinally employed compound of Artemisia annua (L.) and is widely used against a number of diseases. This study presents the effect of an exogenous application of salicylic acid (SA) and gibberellic acid (GA3) on the expression of genes coding for artemisinin pathway enzymes as well as on the biosynthesis of artemisinin. We found a temporary increase in artemisinin content in $A$. annua leaves $12 \mathrm{~h}$ after SA application. However, the transcript levels of all studied genes coding for artemisinin pathway enzymes decreased throughout the period studied and artemisinin content dropped down to an even lower level than in control plants at $168 \mathrm{~h}$ after treatment. In addition, artemisinin content increased, together with up-regulation of genes coding for enzymes of artemisinin biosynthesis pathway, owing to GA3 application. However, down-regulation of all investigated genes was also observed at $72 \mathrm{~h}$ after treatment, probably due to the negative feedback control. As can be seen, both SA and GA3 exogenous applications can increase artemisinin accumulation in different ways. Because of a temporary increase in artemisinin content after SA or GA3 application, it is critical to determine the best harvesting time. Future research should focus on removing the negative feedback mechanism to achieve highyield Artemisia plants.
\end{abstract}

Key words: Artemisia, elicitor, malaria, medicinal plant, secondary metabolite

\section{Introduction}

Artemisinin and its derivatives are obtained from glandular secretory trichomes of Artemisia annua. These compounds are recommended as a first-line treatment for malaria because of low toxicity, acceptable efficacy, easy administration, rapidity of action and other characteristics (Covello et al., 2007; Cui and Su, 2009). In addition, the use of artemisinin is a proven treatment for a number of other diseases, including parasitic diseases such as schistosomiasis, hepatitis B, and a variety of cancers such as breast cancer, human leukemia, colon and small-cell lung carcinomas (Weathers et al., 2006). Low amounts of artemisinin found in the plant tissues encou- raged many researchers to search for the artemisinin biosynthetic pathway (Fig. 1), and also a way to increase its yield in the plant or to reach higher efficiency of production using biotechnological methods. Studying the biochemical pathway of artemisinin synthesis and the mechanism of its regulation could enable us to move toward targeted metabolic engineering, and to achieve that, knowledge of how genes coding for artemisinin pathway enzymes respond to elicitors will be useful.

Salicylic acid is a phenolic phytohormone associated with various physiological processes, including flowering, thermogenesis, stomatal closure and leaf abscission (Raskin, 1992). SA is also a signaling molecule which is

\footnotetext{
* Corresponding author: Department of Horticulture, College of Abouraihan, University of Tehran, Iran; e-mail: mzarem@ut.ac.ir
} 


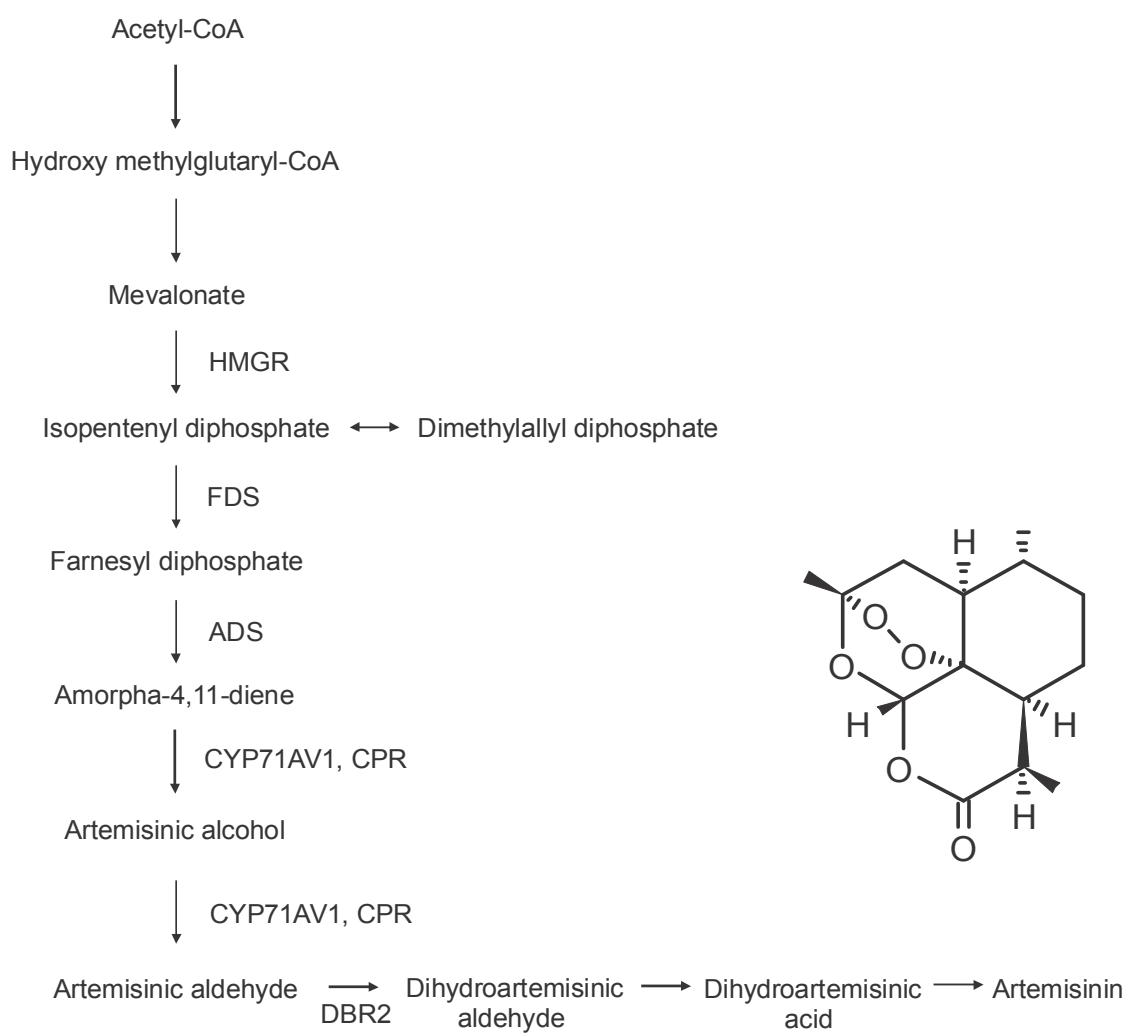

Fig. 1. Scheme of the artemisinin biosynthetic pathway. HMGR, HMG-CoA reductase; FDS, Farnesyl pyrophosphate synthase; ADS, Amorpha-4,11-diene synthase; CYP71AV1, Cytochrome P450 monooxygenase; CPR, cytochrome P450 reductase; DBR2, artemisinic aldehyde $\Delta 11(13)$ reductase 2

involved in plant response to biotic (pathogen infection) and abiotic stresses (e.g. ultraviolet light radiation and ozone contamination) (Rao and Davis, 1999; Senaratna et al., 2000; Halim et al., 2006; Song, 2006; Yuan and Lin, 2008). It has been found that SA induces secondary metabolite biosynthesis in plants (Bulgakov et al., 2002; Wang et al., 2004; Ali et al., 2006; Wang et al., 2007; Khalili et al., 2009; Dong et al., 2010). Published reports have described that SA activated the biosynthesis of artemisinin in the entire $A$. annua plant and it could up-regulate Amorpha-4,11-diene synthase gene through invoking ${ }^{1} \mathrm{O}_{2}$ burst (Pu et al., 2009; Guo et al., 2010). However, the time-course effects of SA on the main artemisinin biosynthesis are still unknown.

Gibberellic acid is another important plant hormone regulating such processes as seed germination, stem elongation, leaf expansion and flower and fruit development (Gomi and Matsuoka, 2003). An application of exogenous GA3 on $A$. annua plants significantly increased the production of artemisinin, up-regulating three genes in its biosynthesis pathway and inducing the conversion of artemisinic acid to artemisinin (Zhang et al., 2005; Banyai et al., 2010). However, in recent research no induction of artemisinin biosynthesis by GA3 was reported (Maes et al., 2011).

Therefore, in the current study, the effects of exogenous applications of SA and GA3 on the time-course production of artemisinin and genes coding for its pathway enzymes were investigated in the whole plant to find possible ways of increasing the artemisinin yield or of targeted metabolic engineering.

\section{Materials and methods}

\section{Plant culture and elicitor treatment}

Seeds of high artemisinin yielding $A$. annua originating from Gonbad in the Golestan province of Iran were obtained from the Iranian Biological Resource Center. The seeds were surface sterilized with $70 \%$ (v/v) ethanol for $5 \mathrm{~min}$, and washed three times with sterile distilled water. The sterilized seeds were placed on wet Whatman paper and kept in a growth chamber with luminance of 


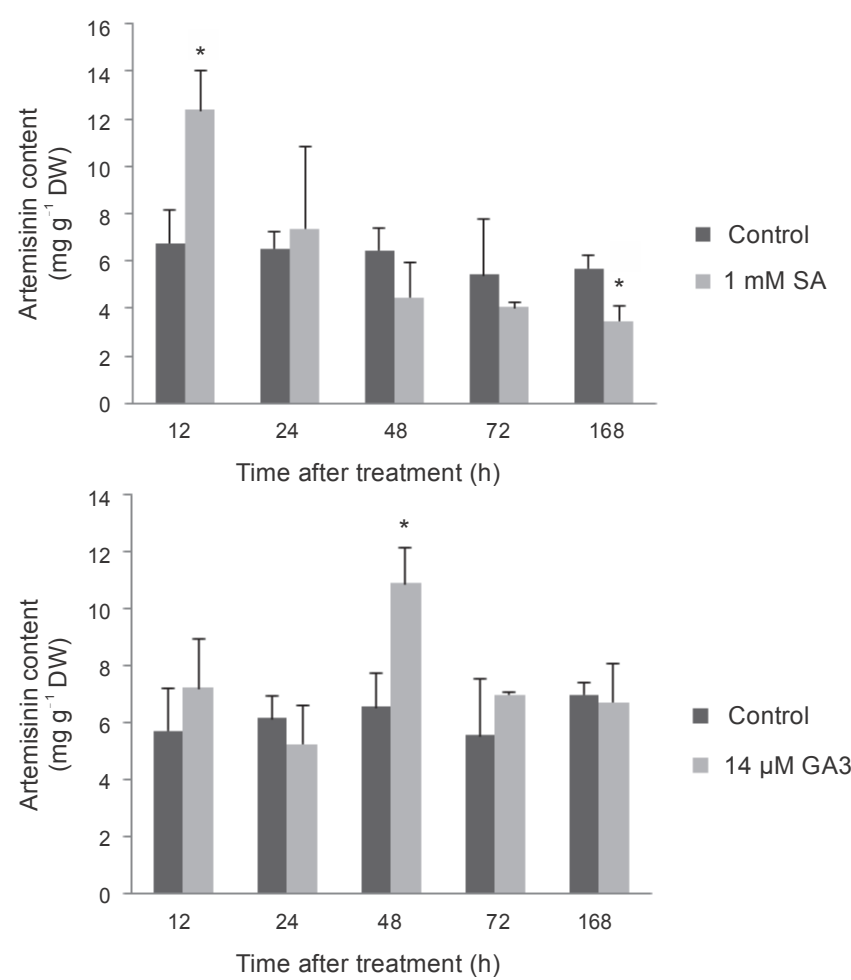

Fig. 2. Influence of SA and GA3 on artemisinin accumulation in $A$. annua plants. Data are mean \pm SD. Asterisk $\left({ }^{*}\right)$ indicates the significance of difference at $0.01<P<0.05$ level by $T$ test when compared to controls

$3000 \mathrm{Lux}$, at $25^{\circ} \mathrm{C}$ and a photoperiod of $16 \mathrm{~h}$ light and $8 \mathrm{~h}$ darkness. After 2 weeks, the seedlings were transferred into plastic pots containing peat-moss and sand (2:1) and were then placed under the same conditions as described above. After 3 months of growth, uniform plants were selected for further experiments. Each plant in an individual pot was sprayed with $14 \mu \mathrm{M}$ GA3 in $0.8 \%$ ethanol (according to Zhang et al. (2005)) or with $1 \mathrm{mM} \mathrm{SA}$ in water (adjusted to $\mathrm{pH} 7.0$ with $\mathrm{NaOH}$, according to $\mathrm{Pu}$ et al. (2009)). In control experiments, $0.8 \%$ ethanol and water were used for spraying. For each sample, five leaves under the third visible leaf in basipetal order were collected at 12, 24, 48, 72 and $168 \mathrm{~h}$ after treatment application. The collected leaves were frozen in liquid nitrogen and stored at $-80^{\circ} \mathrm{C}$ for a gene expression analysis. For the quantification of artemisinin, plants were cut $3 \mathrm{~cm}$ above the soil level and then air dried in an oven at $45^{\circ} \mathrm{C}$ for $48 \mathrm{~h}$ (according to Pu et al. (2009)).

\section{Measurement of artemisinin accumulation}

Artemisinin content in plant tissues was determined by the method described by Ferreira and Gonzalez (2009) with some modifications. Fifty milligrams of dried leaves powder was extracted with $20 \mathrm{ml}$ of petroleum ether (50$70^{\circ} \mathrm{C}$ ) in an ultrasonic bath for $15 \mathrm{~min}$. The supernatant was evaporated with a rotary evaporator. The residue was dissolved in $3 \mathrm{ml}$ of acetonitrile and filtered through a nylon filter $(0.20 \mu \mathrm{m})$ attached to a 5 -ml syringe. The samples were assayed under the following isocratic highperformance liquid chromatography with UV detector (HPLC-UV) conditions: Nucleosil 100 C18 column (125 $\times 4.0 \mathrm{~mm}, 5 \mu \mathrm{m}$ ), a mobile phase of acetonitrile and $0.1 \%$ cold acetic acid $(60: 40, \mathrm{v} / \mathrm{v})$, flow rate of $0.7 \mathrm{ml} \mathrm{min}^{-1}$, wave length of $210 \mathrm{~nm}$ and column temperature of $25^{\circ} \mathrm{C}$. Artemisinin (purity $>97 \%$ ) was provided by the Institute of Medicinal Plants, Iran. The artemisinin standard solutions with concentrations of $0.2-1 \mathrm{mg} \mathrm{ml}^{-1}$ were prepared and used to plot a standard curve of artemisinin.

\section{Expression analysis of genes coding for artemisinin pathway enzymes}

At different time points after chemical treatments of A. annua plants, $100 \mathrm{mg}$ of leaves were collected and used for RNA extraction. Total RNA was isolated with aRNeasy ${ }^{\circledR}$ Plant Mini Kit (Qiagen) and cDNA was generated using a First Strand cDNA Synthesis Kit (Fermentase) according to the manufacturer's instructions. For qPCR amplification, the specific primers for genes coding for artemisinin pathway enzymes (including HMG-CoA reductase $(H M G R)$, farnesyl pyrophosphate synthase $(F D S)$, Amorpha-4,11-diene synthase ( $A D S$ ), cytochrome P450 monooxygenase (CYP71AV1), cytochrome $\mathrm{P} 450$ reductase $(C P R)$ and artemisinic aldehyde $\triangle 11(13)$ reductase 2 (DBR2), with their respective accession numbers AF142473.1, AF112881.1, DQ241826.1, DQ872632.1, DQ984181.1 and EU704257, were obtained from our previous work (Zare Mehrjerdi et al., 2013; Supplementary Table S1). Primers for $18 \mathrm{~S}$ rRNA, the internal reference gene, were designed according to Zeng et al. (2008). Real-time SYBR green PCR cycles were carried out under the following conditions: $95^{\circ} \mathrm{C} / 30$ s followed by 35 cycles of $95^{\circ} \mathrm{C} / 10 \mathrm{~s}, 60^{\circ} \mathrm{C} / 10 \mathrm{~s}$ and $72^{\circ} \mathrm{C} / 30 \mathrm{~s}$. The quantification of transcripts was carried out using an iQ5 (Bio-Rad, United States) machine and calculations were based on the $2^{-\triangle \Delta C T}$ comparative method (Livak and Schmittgen, 2001).

\section{Statistical analysis}

Two biological replicates (each of them with three technical replications) were used for the analysis. Fold 

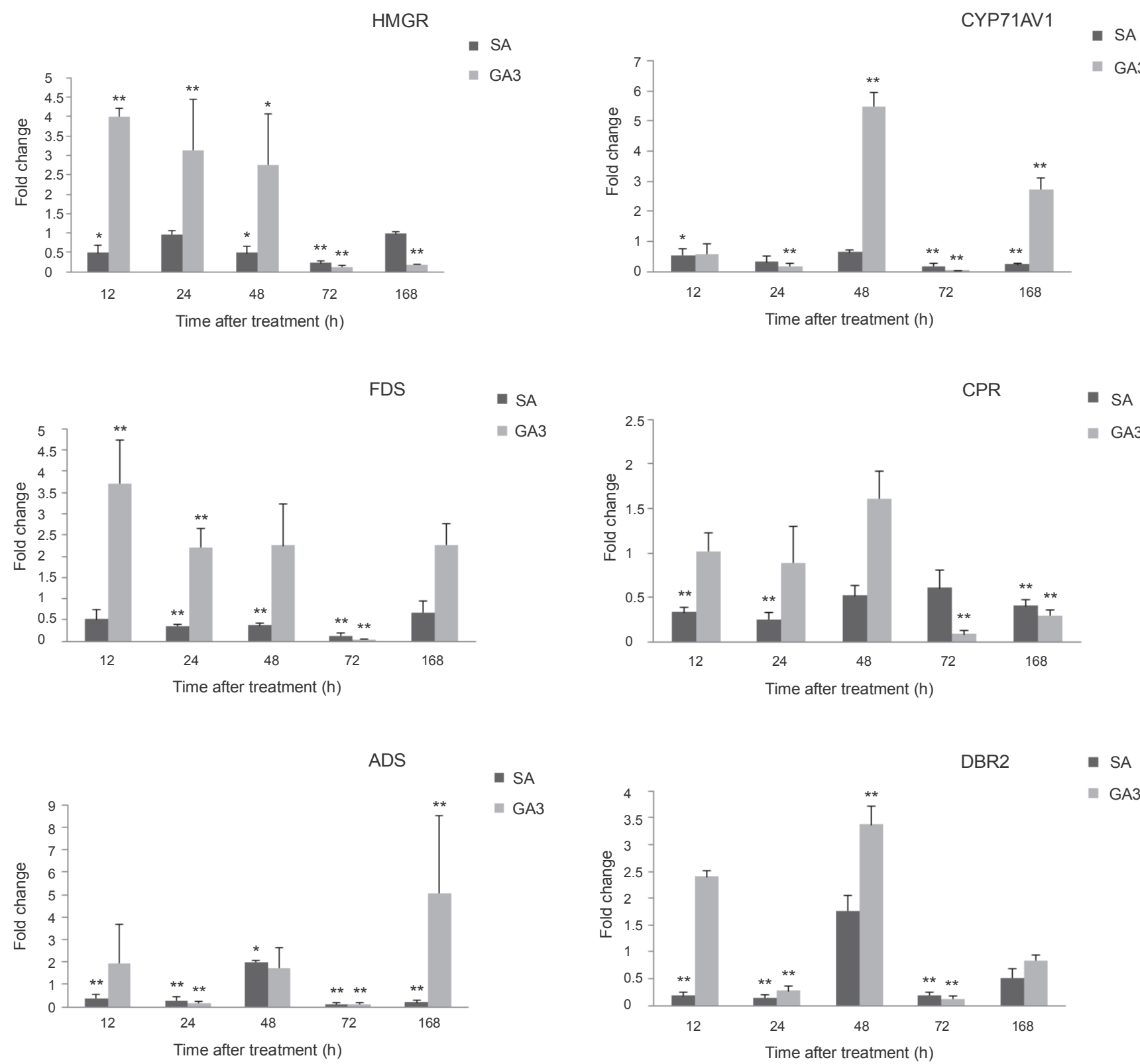

Fig. 3. Changes in HMGR, FDS, ADS, CYP71AV1, CPR and DBR2 gene transcript levels in $A$. annua plants treated by SA and GA3. Data are the means of $2^{-\triangle \Delta \mathrm{CT}} \pm \mathrm{SD}$. Statistical analyzes using a T-test were carried out for significant differences between treated plants and the control. Asterisks ( $\left.{ }^{*}: 0.01<P<0.05 ;{ }^{* *}: P<0.01\right)$ indicate the significance of difference between treated plants when compared to controls

change values were expressed as the mean \pm SD. Statistical analyzes were performed with T-test. The significance level was set at 0.05 .

\section{Results and discussion}

In the current study, we focused our investigation on the influence of two plant hormones (SA and GA) on artemisinin synthesis pathway.
We found that after an exogenous application of SA, the artemisinin content was temporarily increased at $12 \mathrm{~h}$ and then gradually decreased by $63 \%$ compared to its level in the control plant at $168 \mathrm{~h}$ (Fig. 2). The increase in artemisinin content at $12 \mathrm{~h}$ after SA application in our study is in agreement with previous studies $(\mathrm{Pu}$ et al., 2009; Guo et al., 2010). It was hypothesized that SA can promote a conversion of dihydroartemisinic acid 
into artemisinin in a non-enzymatic photo-oxidative step, where ROS generation results in an increase in the artemisinin content (Wallaart et al., 1999; Brown and Sy, 2004). However, after SA application, the increased artemisinin content was not correlated with up-regulation of genes coding for enzymes of the artemisinin biosynthesis pathway. Interestingly, all of the studied genes were down-regulated in response to SA during the period studied (Fig. 3).

In GA3-treated plants, the transcript levels of $H M G R$ and $F D S$ increased approximately 4 -fold $12 \mathrm{~h}$ after GA3 application, then this increase continued until $24 \mathrm{~h}$ with the levels 3- and 2-fold higher compared to the controls, respectively. However, the expression levels of $A D S$, $C Y P 71 A V 1$ and $D B R 2$ were decreased 5.5, 5.5 and 3.5 fold, respectively. At $48 \mathrm{~h} H M G R, C Y P 71 A V 1$ and $D B R 2$ were up-regulated 3-, 5.5- and 3.5-fold, respectively. In this study, most of the studied genes (HMGR, FDS, $A D S, C Y P 71 A V 1$ and $D B R 2$ ) were up-regulated after GA3 application together with an increase in the level of artemisinin at $48 \mathrm{~h}$ after treatment, which was $66 \%$ higher than the control (Figs. 2 and 3). However, Zhang et al. (2005) reported no difference in the transcription pattern of $A D S$ gene by RNA gel blot analysis, while upregulation of $F D S, A D S$ and $C Y P 71 A V 1$ in response to GA3 has been reported by Banyai et al. (2010). At $72 \mathrm{~h}$ after treatment, all of the studied genes were down-regulated, ranging from 7.5- to 46.5-fold, which was accompanied with a consequent reduction in artemisinin to the same level as in control plants. At $168 \mathrm{~h}, H M G R$ and $C P R$ transcript levels decreased 5.5- and 3.5-fold, respectively, while $A D S$ and $C Y P 71 A V 1$ transcript levels increased 2.5- and 5-fold relative to control, respectively (Figs. 2 and 3). Several reports have shown that artemisinin has a phytotoxic effect on Artemisia plants and there is a feedback control on artemisinin production (Arsenault et al., 2010a, 2010b; Zare Mehrjerdi et al., 2013), which could be one of the explanations for the observed down-regulation at 72 and $168 \mathrm{~h}$.

It can be concluded that SA and GA can increase artemisinin content in different ways. Since artemisinin accumulation following a phytohormone application is time-dependent and temporary, the harvesting time of the plant should be carefully determined. Furthermore, it seems that the negative feedback mechanism is one of the key challenges to achieving high artemisinin-yielding plants.

\section{Acknowledgments}

This study was funded by the University of Tehran; contract number 7101010/1/03. We are grateful to the Institute of Medicinal Plants, Iran, for giving us artemisinin for the use in our study.

\section{References}

Ali M.B., Yu K.W., Hahn E.J., Paek K.Y. (2006) Methyl jasmonate and salicylic acid elicitation induces ginsenosides accumulation, enzymatic and non-enzymatic antioxidant in suspension culture Panax ginseng roots in bioreactors. Plant Cell Rep. 25: 613-620.

Arsenault P.R., Vail D., Wobbe K.K., Erickson K., Weathers P.J. (2010a) Reproductive development modulates gene expression and metabolite levels with possible feedback inhibition of artemisinin in Artemisia annua. Plant Physiol. 154: 958-968.

Arsenault P.R., Vail D.R., Wobbe K.K., Weathers P.J. (2010b) Effect of sugars on artemisinin production in Artemisia annua L.: transcription and metabolite measurements. Molecules 15: 2302-2318.

Banyai W., Mii M., Supaibulwatana K. (2010) Enhancement of artemisinin content and biomass in Artemisia annua by exogenous GA(3) treatment. Plant Growth Regul. 63: 4554.

Brown G.D., Sy L.K. (2004) In vivo transformations of dihydroartemisinic acid in Artemisia annua plants. Tetrahedron 60: 1139-1159.

Bulgakov V.P., Tchernoded G.K., Mischenkol N.P., Khodakovskaya M., Glazunov V.P., Radchenko S.V., Zvereva E.V., Fedoreyev S.A., Zhuravlev Y.N. (2002) Effect of salicylic acid, methyl jasmonate, ethephon and cantharidin on anthraquinone production by Rubia cordifolia callus cultures transformed with the rolB and rolC genes. J. Biotechnol. 97: 213-221.

Covello P.S., Teoh K.H., Polichuk D.R., Reed D.W., Nowak G. (2007) Functional genomics and the biosynthesis of artemisinin. Phytochemistry 68: 1864-1871.

Cui L.W., Su X.Z. (2009) Discovery, mechanisms of action and combination therapy of artemisinin. Expert Rev. AntiInfect Ther. 7: 999-1013.

Dong J.A., Wan G.W., Liang Z.S. (2010) Accumulation of salicylic acid-induced phenolic compounds and raised activities of secondary metabolic and antioxidative enzymes in Salvia miltiorrhiza cell cultures. J. Biotechnol. 148: 99-104.

Ferreira J.F.S., Gonzalez J.M. (2009) Analysis of underivatized artemisinin and related sesquiterpene lactones by highperformance liquid chromatography with ultraviolet detection. Phytochem. Anal. 20: 91-97.

Gomi K., Matsuoka M. (2003) Gibberellin signalling pathway. Curr. Opin. Plant Biol. 6: 489-493.

Guo X.X., Yang X.Q., Yang R.Y., Zeng Q.P. (2010) Salicylic acid and methyl jasmonate but not Rose Bengal enhance artemisinin production through invoking burst of endogenous singlet oxygen. Plant Sci. 178: 390-397. 
Halim V.A., Vess A., Scheel D., Rosahl S. (2006) The role of salicylic acid and jasmonic acid in pathogen defence. Plant Biol. 8: 307-313.

Khalili M., Hasanloo T., Tabar S.K.K., Rahnama H. (2009) Influence of exogenous salicylic acid on flavonolignans and lipoxygenase activity in the hairy root cultures of Silybum marianum. Cell Biol. Int. 33: 988-994.

Livak K.J., Schmittgen T.D. (2001) Analysis of relative gene expression data using real-time quantitative $P C R$ and the 2(T)(-Delta Delta C) method. Methods 25: 402-408.

Maes L., Van Nieuwerburgh F.C.W., Zhang Y.S., Reed D.W., Pollier J., Casteele S., Inze D., Covello P.S., Deforce D.L.D., Goossens A. (2011) Dissection of the phytohormonal regulation of trichome formation and biosynthesis of the antimalarial compound artemisinin in Artemisia annua plants. New Phytol. 189: 176-189.

Pu G., Ma D., Chen J., Ma L., Wang H., Li G., Ye H., Liu B. (2009) Salicylic acid activates artemisinin biosynthesis in Artemisia annua L. Plant Cell Rep. 28: 1127-1135.

Rao M.V., Davis K.R. (1999) Ozone-induced cell death occurs via two distinct mechanisms in Arabidopsis: the role of salicylic acid. Plant J. 17: 603-614.

Raskin I. (1992) Salicylate, a New Plant Hormone. Plant Physiol. 99: 799-803.

Senaratna T., Touchell D., Bunn E., Dixon K. (2000) Acetyl salicylic acid (Aspirin) and salicylic acid induce multiple stress tolerance in bean and tomato plants. Plant Growth Regul. 30: 157-161.

Song J.T. (2006) Induction of a salicylic acid glucosyltransferase, AtSGT1, is an early disease response in Arabidopsis thaliana. Mol. Cells 22: 233-238.

Wallaart T.E., van Uden W., Lubberink H.G.M., Woerdenbag H.J., Pras N., Quax W.J. (1999) Isolation and identification of dihydroartemisinic acid from Artemisia annua and its possible role in the biosynthesis of artemisinin. J. Nat. Prod. 62: 430-433.

Wang Y.D., Wu J.C., Yuan Y.J. (2007) Salicylic acid-induced taxol production and isopentenyl pyrophosphate biosynthesis in suspension cultures of Taxus chinensis var. mairei. Cell Biol. Int. 31: 1179-1183.

Wang Y.D., Yuan Y.J., Wu J.C. (2004) Induction studies of methyl jasmonate and salicylic acid on taxane production in suspension cultures of Taxus chinensis var. mairei. Biochem. Eng. J. 19: 259-265.

Weathers P.J., Elkholy S., Wobbe K.K. (2006) Artemisinin: the biosynthetic pathway and its regulation in Artemisia annua, a terpenoid-rich species. In Vitro Cell Dev. Biol. Plant 42: 309-317.

Yuan S., Lin H.H. (2008) Role of salicylic acid in plant abiotic stress. Z. Naturforsch. C. 63: 313-320.

Zare Mehrjerdi M., Bihamta M.R., Omidi M., Naghavi M.R., Soltanloo H., Ranjbar M. (2013) Effects of exogenous methyl jasmonate and 2-isopentenyladenine on artemisinin production and gene expression in Artemisia annua. Turk. J. Bot. 37: 499-505.

Zeng Q.P., Chang Z., Yin L.L., Yang R.Y., Zeng X.M., Ying H., Feng L.L., Yang X.Q. (2008) Cloning of artemisinin biosynthetic cDNAs and novel ESTs and quantification of low temperature-induced gene overexpression. Sci. China. C Life Sci. 51: 232-244.

Zhang Y.S., Ye H.C., Liu B.Y., Wang H., Li G.F. (2005) Exogenous $G A(3)$ and flowering induce the conversion of artemisinic acid to artemisinin in Artemisia annua plants. Russian J. Plant Physiol. 52: 58-62. 